\title{
RANCANG BANGUN GAME EDUKASI BERBASIS ANDROID PEMBANTU SISTEM KEGIATAN BELAJAR MENGAJAR (KBM) MATA PELAJARAN KOMPUTER UNTUK SEKOLAH
}

\author{
Teuku Muhammad Fawaati H.S ${ }^{1}$, Tito Budi Raharo ${ }^{2}$ \\ ${ }^{1,2}$ Universitas Mitra Indonesia
}

\begin{abstract}
In the activities of Computer subjects especially the material "Computer Hardware and Software" subject teachers are less than optimal in utilizing and empowering learning resources. Students are less able to develop themselves and tend to be forced to memorize or remember the material presented. The ability of students who are still low in identifying the types and functions of computer hardware, the habit of playing games after school, so that learning outcomes in computer subjects the material "Knowing Computer Hardware and Software" has not been satisfactory. The system development method uses the System Development Life Cycle (SDLC) method and the system design uses UML. The implementation of this system uses Construct 2, as well as system testing using the Black Box. The results achieved are Android-based Educational Game applications to facilitate students in understanding the learning process at school.
\end{abstract}

Keywords: Game; System Development Life Cycle; UML

\begin{abstract}
Abstrak
Pada kegiatan mata pelajaran Komputer khususnya materi “Perangkat Keras Komputer dan Perangkat Lunak” guru mata pelajaran kurang optimal dalam memanfaatkan maupun memberdayakan sumber pembelajaran. Siswa kurang bisa mengembangkan diri dan cenderung dipaksa untuk menghafal atau mengingat materi yang disampaikan. Kemampuan siswa yang masih rendah dalam mengidentifikasi jenis-jenis dan fungsi perangkat keras Komputer, kebiasaan suka bermain Game setelah pulang sekolah, sehingga Hasil belajar pada mata pelajaran komputer materi "Mengenal Perangkat Keras Komputer dan Perangkat Lunak" belum memuaskan. Metode pengembangan sistem menggunakan metode System Development Life Cycle (SDLC) dan perancangan sistem menggunakan UML. Implementasi sistem ini menggunakan Construct 2, serta pengujian sistem menggunakan Black Box. Hasil yang dicapai yaitu aplikasi Game Edukasi berbasis android untuk mempermudah siswa dalam memahami proses pembelajaran di sekolah.
\end{abstract}

Kata kunci: Game; System Development Life Cycle; UML

\section{PENDAHULUAN}

Saat ini, game digital menjadi bagian dari aktivitas kehidupan seseorang. Dukungan teknologi teknologi seluler dan komputer telah membawa game digital sebagai salah satu alat pembelajaran. Kaitannya dengan pembelajaran, game digital tidak hanya menghadirkan kegiatan yang immersive dan menyenangkan, melainkan kegiatan yang terkait dengan konten pembelajaran untuk mencapai tujuan tertentu (Setiawan et al, 2019). Untuk menunjang proses pembelajaran yang inovatif dan digital, maka diperlukan suatu proses pembelajaran berbasis android berbentuk Game Edukasi yang perosesnya disesuaikan dengan kebutuhan dan kondisi dunia pendidikan. Alasan Game Edukasi berbasis android adalah agar dapat membantu kegiatan belajar mengajar (KBM), karena Game Edukasi adalah salah satu jenis media yang digunakan dalam memberikan pengajaran yang berupa permainan, dengan tujuan untuk merangsang daya pikir dan meningkatkan konsentrasi melalui media yang unik dan menarik, dengan mengidentifikasikan bahwa Game Edukasi bertujuan untuk menunjang proses belajar mengajar dengan kegiatan yang menyenangkan dan lebih kreatif (Handriyantini, 2009) dan Game Edukasi juga merupakan permainanan yang dibuat 
dengan tujuan pembelajaran yang bukan hanya bermaksud menghibur tetapi diharapkan bisa menambah wawasan dan pengetahuan (Novia Desta, 2016). Selain itu, Game memberikan peluang terhadap pebelajar untuk mengembangkan keterampilan, pengetahuan dan sikap melalui prinsip dan fitur yang digunakan di dalam game play (Nikiforidou, 2018).

Dari pemaparan diatas peneliti tertarik untuk membuat aplikasi Game Edukasi berbasis android untuk mempermudah siswa dalam memahami proses pembelajaran di sekolah, pemanfaatan Game Edukasi juga dapat meningkatkan mutu sekolah, serta dapat mempermudah proses pembelajaran yang menyenangkan, lebih kreatif, merangsang daya pikir, meningkatkan konsentrasi, menambah wawasan dan pengetahuan para siswa.

\section{KERANGKA TEORI}

\subsection{Pengertian Perancangan}

Sedangkan Muharto (2016) mendefinsikan perancangan sistem dalam bukunya yang berjudul Metode Penelitian Sistem Informasi, perancangan sistem adalah suatu fase dimana diperlukan suatu keahlian perancangan untuk elemen-elemen komputer yang akan mengunakan sistem yaitu pemilihan peralatan dan program komputer untuk sistem yang baru.

\subsection{Pengertian Game Edukasi}

Novia Desta (2016) mengatakan Game Edukasi adalah permainan yang dibuat dengan tujuan pembelajaran yang bukan hanya bermaksud menghibur sehingga diharapkan bisa menambah wawasan pengetahuan. Selain itu, menurut Firdaus dan Nugroho (2016), Game edukasi adalah salah satu contoh dari media pembelajaran yang menerapkan pola learning by doing. Pola ini menuntut pemainnya untuk tidak mengulangi kegagalan dalam setiap tahap game. Dari pola yang diterapkan game edukasi, pemain akan melakukan pembelajaran secara mandiri.

\subsection{Pengertian Android}

Menurut Silvia, Haritman dan Muladi (2014) “Android adalah platform open source yang komprehensif dan dirancang untuk mobile devices. Dikatakan komprehensif karena Android menyediakan semua tools dan frameworks yang lengkap untuk pengembangan aplikasi pada suatu mobile device. Sistem Android menggunakan database untuk menyimpan informasi penting yang diperlukan agar tetap tersimpan meskipun device dimatikan."

\subsection{Metode Pengembangan System Development Life Cycle (SDLC)}

System Development Life Cycle (SDLC) adalah metodologi klasik yang digunakan untuk mengembangkan, memelihara dan menggunakan sistem informasi. Siklus hidup sistem itu sendiri merupakan metodologi, tetapi polanya lebih dipengaruhi oleh kebutuhan untuk mengembangkan sistem yang lebih cepat. Pengembangan sistem yang lebih cepat dapat dicapai dengan peningkatan siklus hidup dan penggunaan peralatan pengembangan berbasis komputer (Rosa and Shalahudin,2018).

\subsection{Pengertian Bahasa Pemodelan Pengembangan Sistem}

Bahasa Pemodelan Pengembangan Sistem Unified Modeling Language (UML) adalah salah satu standar bahasa yang banyak digunakan di dunia industri untuk mendefinisikan requirement, membuat analisis \& desain, serta menggambarkan arsitektur dalam pemrograman berorientasi objek. (Rosa \& Shalahuddin, 2018). 


\section{METODOLOGI}

Dalam pengembangan sistem booking service ini akan dirancang menggunakan UML, yang merupakan suatu bahasa yang menjelaskan sebuah sistem informasi secara visual dengan diagram yang membentuk interaksi antara pengguna dengan sistem itu sendiri. Selain itu diagram tersebut juga menjelaskan spesifikasi, rancang bangun sebuah sistem, pembuatan model sistem dan mendokumentasikan aspek-aspek yang dibutuhkan oleh sebuah sistem yang akan dibuat. UML dapat digunakan untuk memvisualisasikan, menentukan, membangun, dan mendokumentasikan sebuah sistem perangkat lunak.

\section{HASIL DAN PEMBAHASAN}

\subsection{Desain Sistem}

Bab ini akan menjelaskan tentang pembuatan aplikasi game edukasi, dengan memberikan contoh implementasi form, Implementasi merupakan tahap dimana sistem dibuat dan siap digunakan pada tahap sebenarnya, berikut adalah hasil penelitian yang dibuat:

\subsubsection{Use Case Diagram}

Use case diagram atau diagram use case merupakan pemodelan untuk kelakuan (behavior) sistem informasi yang akan dibuat. Use case mendeskripsikan sebuah interaksi antara satu atau lebih aktor dengan sistem informasi yang akan dibuat.

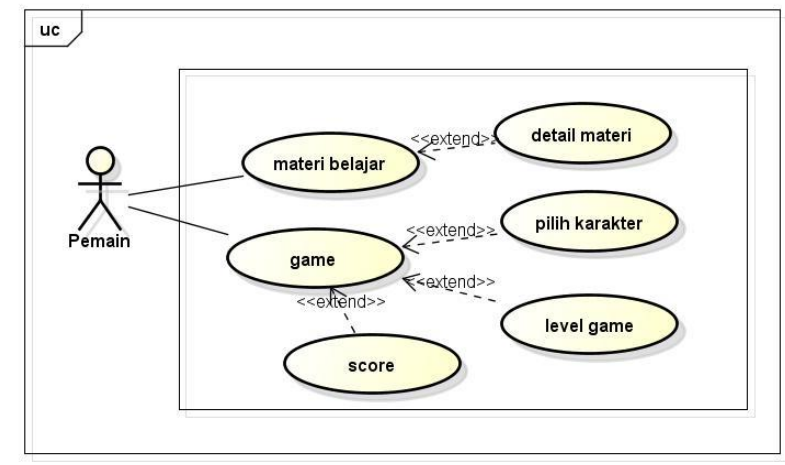

Gambar 1. Usecase Diagram

\subsubsection{Activity Diagram}

Activity diagram atau diagram aktivitas menggambarkan workflow (aliran kerja) atau aktivitas dari sebuah sistem atau proses bisnis. Yang perlu diperhatikan disini adalah bahwa diagram aktivitas menggambarkan aktivitas sistem bukan apa yang dilakukan aktor, jadi aktivitas yang dapat dilakukan oleh sistem. 


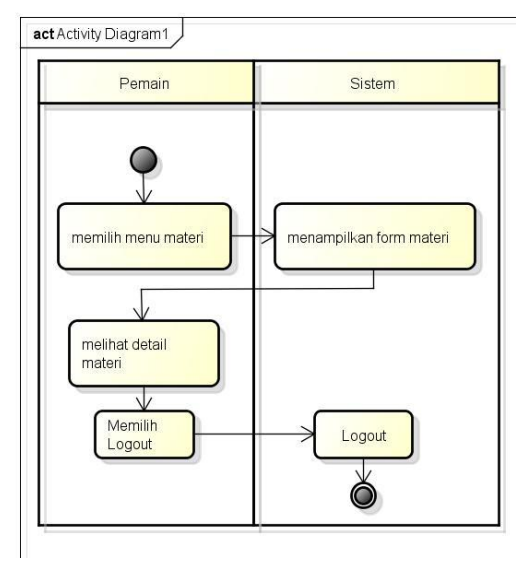

Gambar 2. Activity Diagram Materi

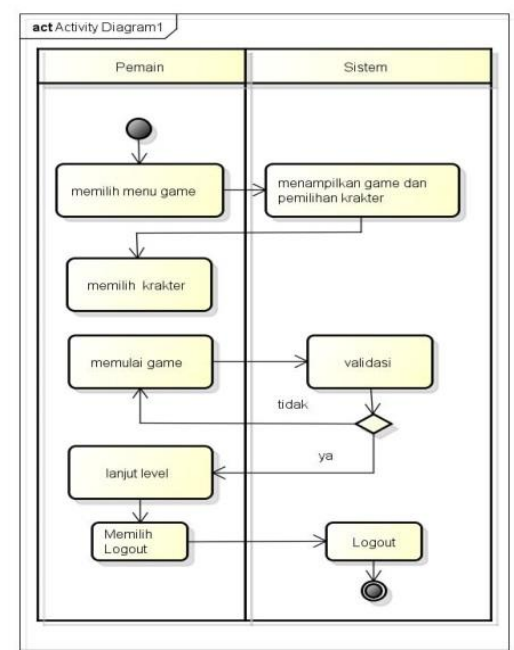

Gambar 3. Activity Diagram Game

\subsection{Rancangan Interface}

Rancangan desain form menjelaskan atau mendeskripsikan rancangan antarmuka dari program yang akan dibuat. Berikut adalah rancangan yang akan dibuat :

\subsubsection{Menu Utama}

Pada menu utama adalah tampilan awal aplikasi game edukasi. Pada tampilan ini terdapat pilihan menu yaitu menu materi untuk melihat seputar materi yang diberikan, dan menu game digunakan untuk melakukan permainan pada aplikasi yang diberikan sebagai pembantu dalam pemberlajaran. Rancangan antarmuka menu utama dapat dilihat pada gambar berikut: 


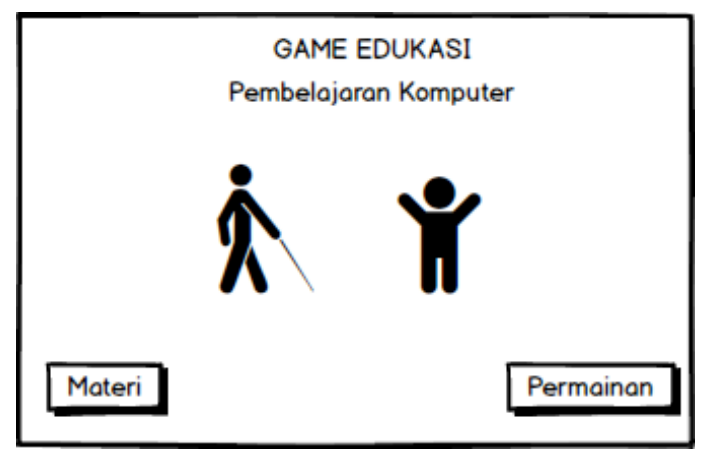

Gambar 4. Menu Utama

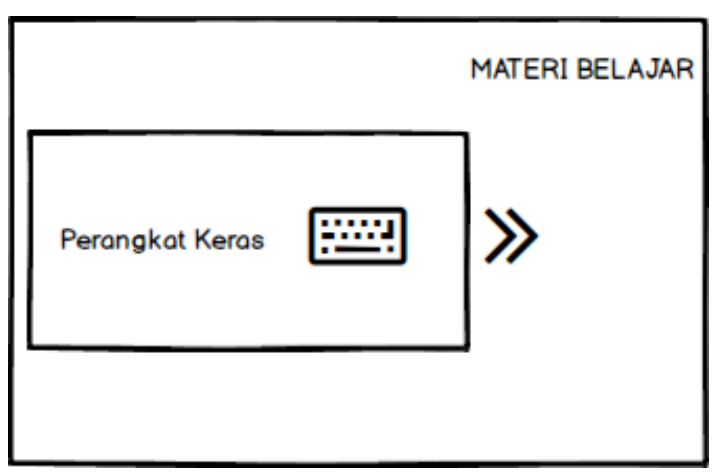

Gambar 5. Menu Materi

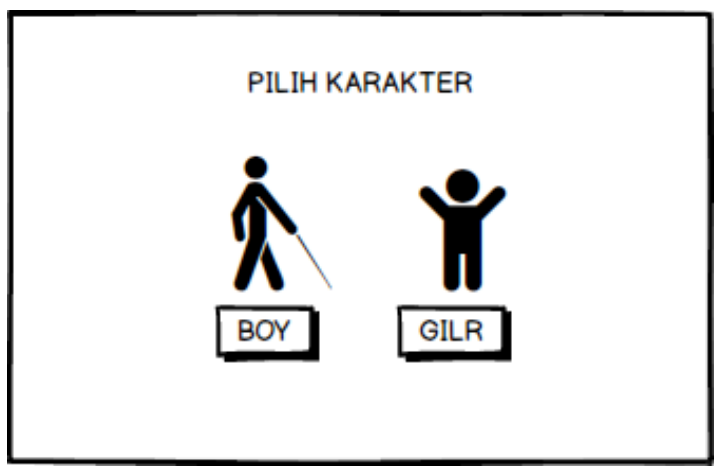

Gambar 6. Menu Pemilihan Karakter

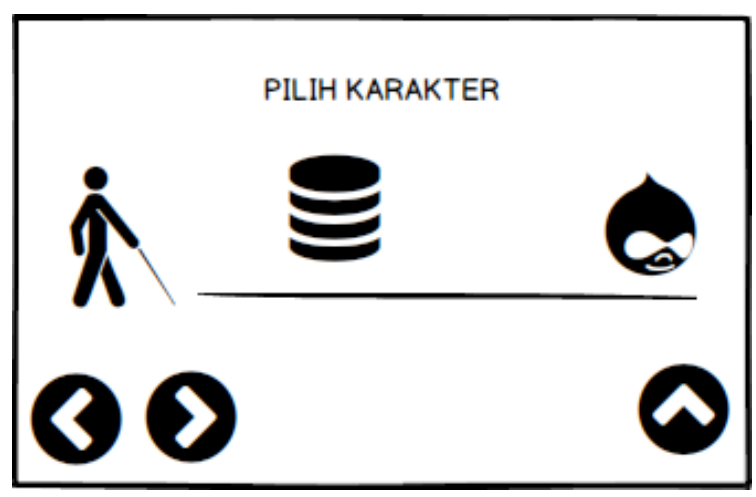

Gambar 7. Menu Game 


\subsection{Pengujian Sistem Black Box}

Pengujian sistem dilakukan untuk menjamin kualitas dan juga mengetahui kelemahan dari sistem. Tujuan dari pengujian ini adalah untuk menjamin bahwa perangkat lunak yang dibangun memiliki kualitas yang handal, yaitu mampu merepresentasikan kajian pokok dari spesifikasi, analisis, perancangan dan pengkodean dari perangkat lunak itu sendiri. Beberapa kasus dan hasil pengujian yang telah dilakukan, diantaranya adalah sebagai berikut:

Tabel 1. Pengujian Aplikasi Game

\begin{tabular}{|c|c|c|c|}
\hline No & Gambar dan Skenario Pengujian & $\begin{array}{l}\text { Hasil yang } \\
\text { Diharapkan }\end{array}$ & Kesimpulan \\
\hline
\end{tabular}

1

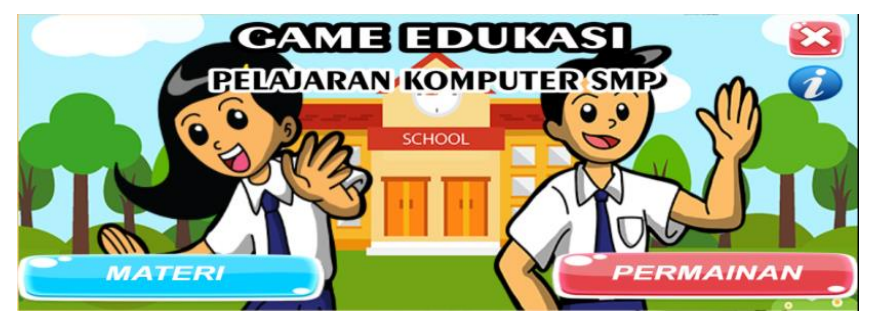

Membuka aplikasi maka akan masuk ke tampilan awal game

2

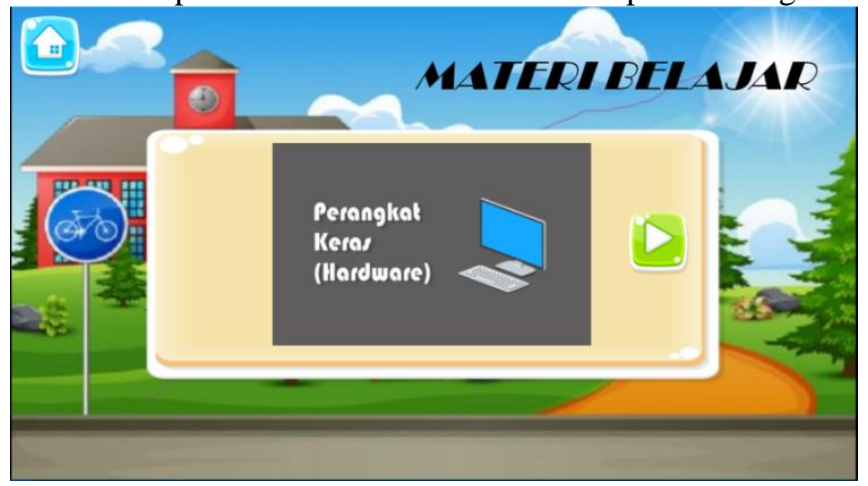

Pada menu utama terdapat menu materi maka akan masuk kedalam tampilan materi

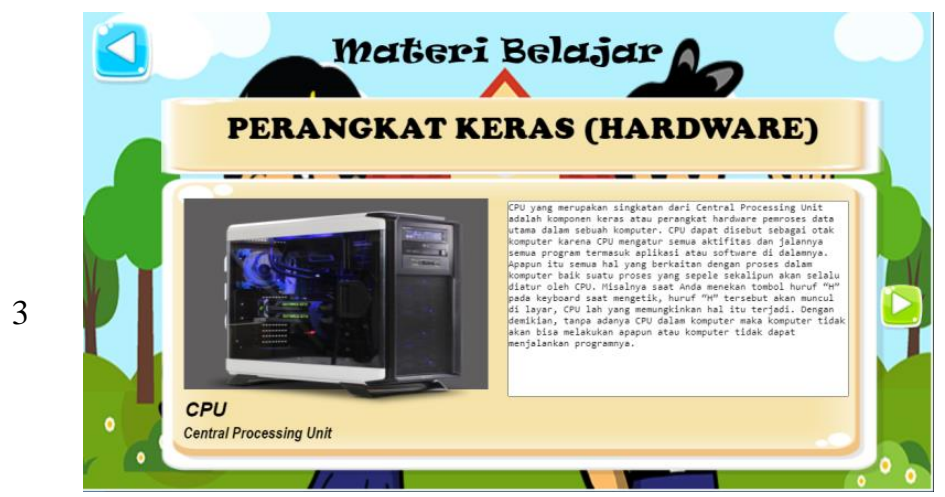

Pada tampilan materi terdapat tombol detail materi jika diklik maka akan masuk ke tampilan detail materi

\section{Masuk ke halaman \\ utama \\ Diterima}

Akan masuk

ke tampilan materi

Diterima

Akan
tampilan
detail materi

Diterima 


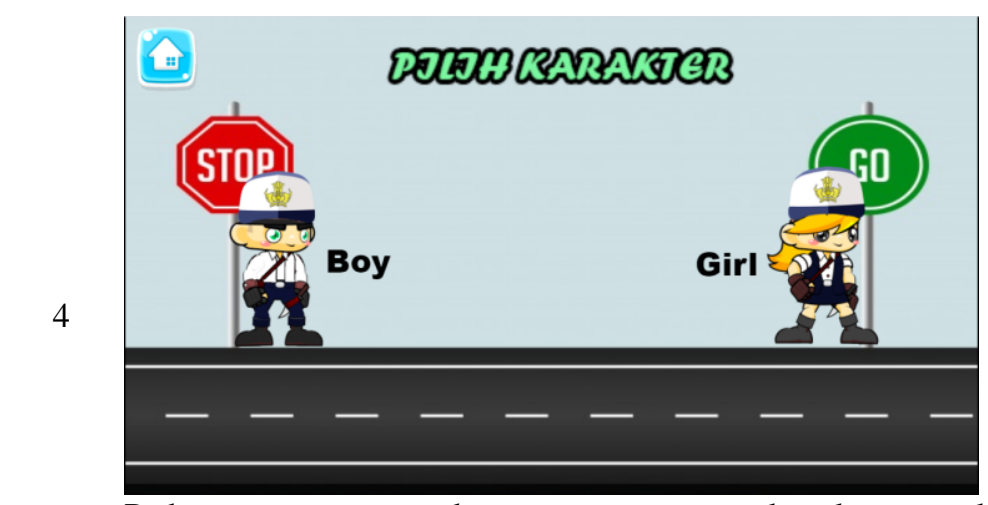

Akan
tampilan
pilihan
krakter

Pada menu utama terdapat menu game maka akan masuk kedalam tampilan pemilihan karakter

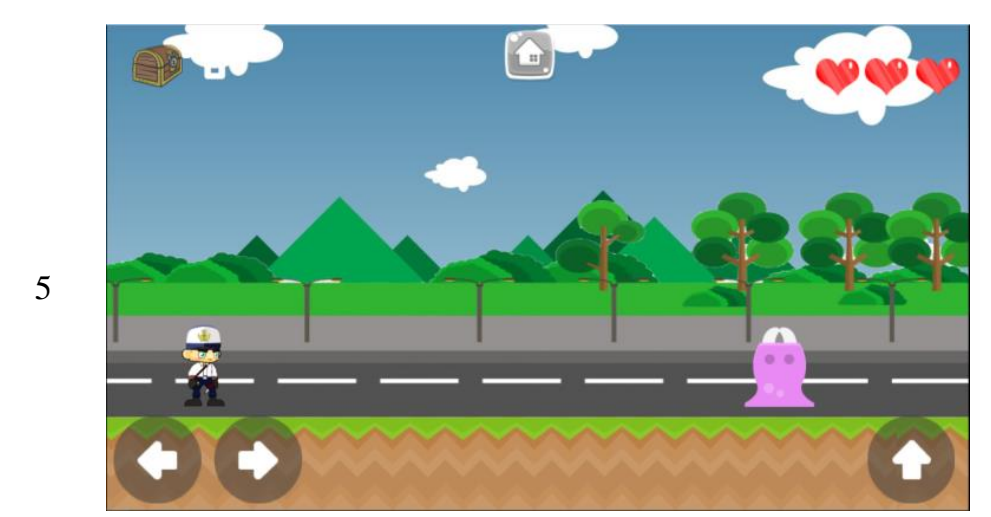

Akan

tampilan

Diterima game

Setelah melakukan pemilihan karakter maka akan tampil tampilan game
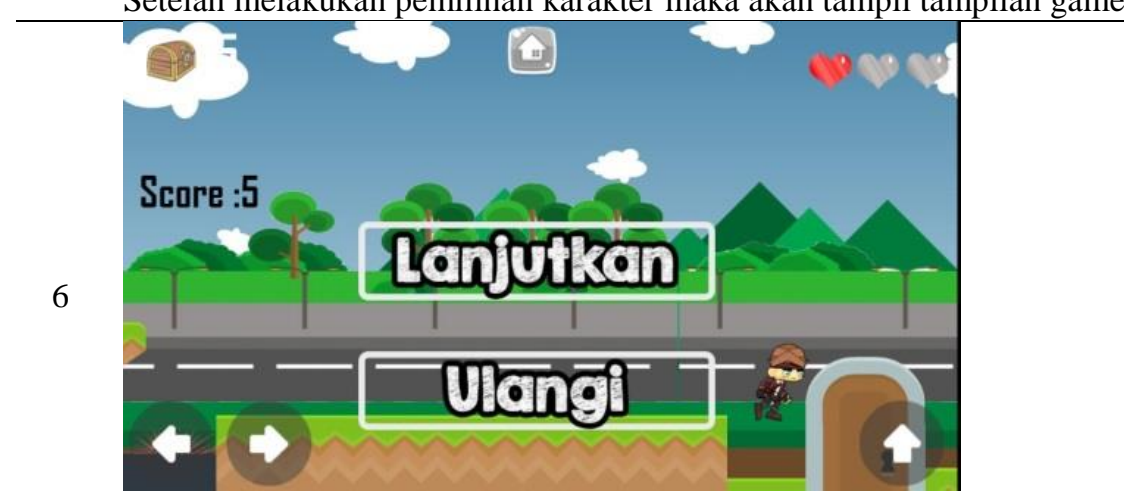

Setelah memainkan game maka akan tampil score untuk lanjut dan berhenti

\section{KESIMPULAN}

Berdasarkan hasil pembahasan yang telah dilakukan, maka dapat disimpulkan sebagai berikut:

1. Metode pembuatan atau pengembangan aplikasi Game Edukasi Berbasis Android menggunakan System Development Life Cycle (SDLC),

2. Aplikasi yang dibangun dapat menambah wawasan dan menghasilkan nilai belajar siswa yang pembelajarannya menggunakan media Game Edukasi Berbasis Android dengan menampilkan score permainan,

3. Penerapan Game Edukasi Berbasis Android dapat meningkatkan hasil belajar siswa pada mata pelajaran komputer disemua sekolah sesuai dengan kurikulum yang ada. 


\section{DAFTAR PUSTAKA}

Handriyantini., 2009. Permainan Edukatif Berbasis Komputer Untuk Siswa Sekolah Dasar. Sekolah Tinggi. Malang. Muharto, Arisandy, Ambarita., 2016. Metode Penelitian Sistem Informasi, Yogyakarta: Deepublish.

A.S., Rosa., Shalahuddin, M. 2018. Rekayasa Perangkat Lunak Terstruktur dan Berorientasi Objek. Bandung: Informatika

Silvia, A. F., Haritman, E., \& Muladi, Y., 2014. Rancang Bangun Akses Kendali Pintu Gerbang Berbasis Arduino Dan Android, 13(1), 1-10.

Firdaus, Muhammad., Nugroho, Handang Wahyu., 2016. Rancang Bangun Game Edukasi Asah Otak Anak Berbasis Android Menggunakan Aplikasi Construct 2. Jurnal Konvergensi, 12(1), 1-10. doi: 10.30996/konv.v12i01.859

Nikiforidou, Z., 2018. Digital Games in the Early Childhood Classroom: Theoretical and Practical Considerations.

Digital Childhoods, 253-265. doi: 10.1007/978-981-10-6484-5_16

Setiwan, Andri., Praherdhiono, Henry., Sulthoni., 2019. Penggunaan Game Edukasi Digital Sebagai Sarana Pembelajaran Anak Usia Dini. Jurnal Inovasi Teknologi Pembelajaran (JINOTEP), 6(1), 39-44. doi: 10.17977/um031v6i12019p039 